\title{
A aventura amorosa do casal contemporâneo
}

Ana Lúcia Stipp Paterniani*

Através da leitura crítica e comentada de diversos autores sobre o tema, procuramos enfocar os aspectos sociais que influenciam a relação do casal.

A justificativa da escolha do nosso objeto de estudo pode ser resumimida nas palavras do psicanalista Abraham Turkenicz (1995): "Não parece haver muita dúvida: a cultura humana recomenda que o viver em casal seja um importante recurso ou de construção de felicidade ou de evitação de infelicidade para a imensa maioria das pessoas". E acrescenta: "Para imitar as gerações anteriores, por uma astúcia da espécie, para uma divisão operacional das tarefas cotidianas, pelas razões que forem, a verdade é que as pessoas continuam constituindo casais. Vivemos numa época em que os casais se desfazem em quantidade como nunca antes na história humana. Isso só ocorre porque as pessoas não deixam de formar casais também em grandes quantidades" (1995).

* Psiquiatra. Pós-Graduada em Educação Sexual pela SBRASH 
Essas constatações nos intrigam e nos dão a impressão de que as pessoas buscam na relação de casal a realização de um objetivo que nem sempre é atingido, um ideal de felicidade que quase nunca é alcançado. O psicoterapeuta Roberto Shinyashiki (1990) ilustra bem essa situação:

"Aparentemente, um casamento é algo muito fácil: duas pessoas se amam, querem construir suas vidas juntas, desejam a mesma coisa e se comprometem a consegui-la juntas. Mas, assim como as crianças dos contos de fadas, as pessoas acabam se desviando dos seus objetivos e das instruções que elas sabem que têm que ser seguidas. E, de repente, o casal João e Maria encontra-se perdido no meio da floresta, prisioneiro de bruxas". Shinyashiki compara o casamento com a floresta encantada e o casal com as crianças dos contos de fadas:

"Os caminhos parecem ser fáceis, mas eles guardam dentro de si perigos, ciladas e armadilhas que exigem virtudes de heróis e sábios para se conseguir chegar ao objetivo. Numa floresta encantada, encontram-se os pássaro,; com os cantos mais maravilhosos, as flores com os perfumes mais inebriantes, mas também a maçã envenenada da Branca de Neve, ou a maldição da Bela Adormecida" (Shinyashiki, 1990).

Talvez o maior conhecimento dos atalhos e das ciladas desse caminho, que é a vida a dois, auxilie cada vez mais casais a atingirem o seu objetivo. Para que possam gozar o exercício do amor e da sexualidade de uma forma livre e plena, desfrutando os prazeres e alegrias da vida em comum a que têm direito. Por isso o interesse em estudar os fatores sócio-culturais relacionados ao sucesso e felicidade dos casais, bem como os que impedem ou desviam desse caminho. Este trabalho pretende trazer a sua modesta colaboração nesse sentido.

"O amor, o trabalho e o conhecimento são as fontes da nossa vida. Deviam também governá-la”.

(Wilhelm Reich)

\section{EM DEFESA DO DESEJO - UMA VISÃO SÓCIO-HISTÓRICA}

“AS motivações para a formação e manutenção dos casais são muito variadas mas há um predomínio crescente, pelo menos a partir do século XVIII. de casais por inclinação. Possivelmente este seja um dos mais importantes indicadores contemporâneos" (Turkenicz, 1995). 
Para compreender melhor os aspectos no que se refere ao amor e à sexualidade na nossa época atual, consideramos importante fazer um breve histórico. O professor Jean-Louis Flandrin (1988), especialista em história do amor e da sexualidade, justifica essa necessidade:

"As dificuldades que nós mesmos encontramos em nossa vida atual, não as herdamos também do passado"? E vai além: "Em realidade não somos livres para recusar nossa herança: ela está grudada à nossa pele. E quanto mais quisermos ignorá-la, mais seremos seus Prisioneiros".

Esse autor quer nos fazer entender que, da mesma forma que a psicanálise tenta encontrar no passado das pessoas a causa das suas dificuldades atuais, também devemos dar atenção ao nosso passado coletivo. Uma vez que também somos seres sociais, talvez também possamos aprender coisas úteis com os nossos antepassados.

\section{"Na parede da memória \\ essa lembrança \\ é o quadro que dói mais.}

Minha dor é perceber

que apesar de termos

feito tudo que fizemos,

Ainda somos os mesmo

e vivemos como nossos pais”.

(Antonio Carlos Belchior)

\subsection{Nos primórdios da civilização: o amor selvagem}

O autor Marcel Blanc (1994) em seu interessante livro "Os herdeiros de Darwin" explica a possível origem do bipedismo como sendo uma necessidade adaptativa dos machos de deixarem as mãos livres para levarem os alimentos à prole e à fêmea. Outra interessante observação desse autor é que as fêmeas da espécie humana não apresentam sinais externos de ovulação e período fértil. Isso a "obrigaria" de certa forma manter o macho sempre por perto para garantir a reprodução da espécie. Baseado nesses e em outros dados, o autor concluiu que possivelmente os casais eram monogâmicos e que a função desse arranjo seria de ordem econômica. reprodutiva e sexual basicamente. Acrescenta porém que a 
diversidade e versatilidade de costumes da natureza humana na esfera da sexualidade têm explicações num sentimento mais profundo: o Amor. E admite a presença deste como também sendo responsável pela atração e união dos casais desde os primódios, mesmo que não fosse o motivo principal naquela época.

\author{
"Quem, de três milênios, \\ não é capaz de se dar conta \\ vive na ignorância, na sombra, \\ à mercê dos dias, do tempo".
}

(Joahann Wolfgang Von Goethe)

\title{
1.2. A Grécia Antiga: a origem de Eros
}

"A mitologia helênica é uma das mais geniais concepções que a humanidade produziu. Os gregos, com suas fantasias, povoaram o céu e a terra, os mares e o mundo subterrâneo de divindades principais e secundárias. Amantes da ordem, instauraram uma precisa categoria intermediária para os semideuses e os heróis. Superando o tempo, ela ainda se conserva com toda a sua serenidade, equilíbrio e alegria. Prodigamente, alimentou a literatura e as artes através dos séculos. A cultura ocidental deve-lhe muito do espírito e do sentido, senão do próprio fato de existir. Os primeiros mitos brotam, pois, da projeção imaginativa que o homem faz das máximas funções da vida: nascimento, amor e morte. E sintetizam tudo que o homem, mediante a inteligência e o sentimento, conseguiu conquistar em face de uma vida que não solicitou, de uma morte que o amedronta e de um amor que o domina" (Enciclopédia Mitologia).

Algumas versões sobre a origem do amor (extraído da Enciclopédia Mitologia):

"Contam os órficos (fiéis seguidores dos ensinamentos do poeta Orfeu), que a Noite era uma ave negra de enormes asas. E, fecundada Pelo vento, pôs um ovo de prata no seio da escuridão original, entre o Céu que havia acima, e a terra que jazia embaixo. Do ovo saiu Eros, o Amor Universal. Eros não gostava de viver escondido nas trevas. For isso sob a luz de Fanes (a Luz) que até então se guardava no ovo de prata, o Amor começou a desnudar a natureza. E uniu o Céu e a terra num abraço violento e apaixonado, do qual nasceu tudo o que faltava nascer". 
Outra versão nos conta que...

"O amor nasceu da Pobreza e de Recurso. Por isso o Amor herda da mãe e permanente carência e o destino de andarilho a do pai a coragem, a decisão, a energia e a astúcia. Das heranças reunidas decorre sua sina singular: nem mortal nem imortal. Ora germina a vive - quando enriquece. Ora morre e de novo renasce. Perenemente transita entre viver, morrer e ressuscitar-. Já a versão do poeta grego Hesíodo mostra que...

"Primeiro surgiu o Caos - espaço aberto, matéria informe. E em seguida a Terra e Eros, o Amor, criador de toda a vida". Essa colocação de Eros logo no começo da seqüência do nascimento dos deuses é intencional e importantíssima: o Amor, força universal de atração é que justifica a união dos seres mortais e imortais. Eros surge pois, com um caráter que conservará para sempre: o de mediador, o intermediário, o que mescla os princípios oposto levando ao equilíbrio e à harmonia. Mas de todos os pensadores antigos foi Platão (427-347 a.C.) o que mais se dedicou a debater o Amor, chegando mesmo a torná-lo um dos pontos centrais de sua construção filosófica. Em seu diálogo "O Banquete", Eros, o Amor, é o medidor entre a sensibilidade e a compreensão pura das coisas.

Somente mais tarde, na época Alexandrina, é que Eros passa a assumir o aspecto de menino travesso, cujo os caprichos são o tormento dos deuses e homens. Para ressaltar a sua imprevisibilidade, irracionalidade e inconstância. Eros torna-se Cupido, uma criança alada que fere os corações com suas flechas. Acontece que Eros acaba ferido pelas próprias setas e apaixona-se pela princesa mortal Psiquê (Alma) e desse romance decorre uma série de aventuras até que Psiquê recebe o privilégio da imortalidade, casa-se com Eros e dessa união nasce... Volúpia!

Nessa estória de Eros e Psiquê, quem tenta por todos os meios atrapalhar a felicidade dos dois são Afrodite (a mãe ciumenta de Eros) e as irmãos da princesa Psiquê.

Talvez uma das lições importantes que podemos aprender com os nossos sábios antepassados gregos é que a Família (na figura de sogros, cunhados, etc.) muitas vezes pode interferir na relação de casal e ser fator de discórdia, Poder perceber os sentimentos de ciúmes e inveja que permeiam tais relações e sobretudo preservar e respeitar um espaço de confiança, privacidade e intimidade só do casal, pode ser uma atitude saudável e terapêutica para a maioria dos casais.

Pelas ricas estórias sobre o Amor nessa época, conclui-se que este sentimento era muito valorizado. Apresenta-se tanto com características divinas, voltadas ao espírito (Agape) bem como humanas, voltada aos prazeres do corpo (Eros). 


\subsection{A Idade Média: amor sagrado $\mathrm{x}$ amor profano}

Com a vinda do cristianismo e o fortalecimento da Igreja, o Amor passa a ser valorizado na sua forma mais espiritual, voltada para Deus, marcado pela dedicação e renúncia. Ao mesmo tempo há uma forte repressão aos prazeres da carne e portanto o amor sexualizado é visto como algo inferior, indigno dos amores sublimes, algo a ser feito somente com prostitutas e considerado pecaminoso. A Cruzadas também favoreciam essa condição de amor platônico e idealizado. Vejamos o relato do historiador Flandrin (1988):

"O estatuto do amor no século XVI tinha cânticos de amor platônico e cânticos do amor carnal. Por outro lado, os moralistas eclesiáticos tinham a tendência a condenar a paixão amorosa sob todas as formas, sem se preocuparem em distinguir, como se têm feito muito no século XX o verdadeiro amor do simples desejo. As ligações conjugais tinham por função estabelecer alianças entre famílias e assegurar a transmissão de heranças, os namoricos arriscavam na realidade subverter a ordem social".

A Igreja condenava todo amor profano como contrário ao amor sagrado. Insistia inclusive sobre os perigos do amor entre esposos. Ao longo da Idade Média os teólogos repetiam: "Adúltero é também aquele que é por demais ardente e apaixonado por sua mulher".

"Fara a antiga moral cristã, a sexualidade nos é dada somente para procriar e qualquer outro uso seria perverter a obra de Deus" Flandrin (1988).

Por isso herdamos dessa época toda a culpa que acompanha o prazer do exercício da sexualidade, mesmo entre os casados. Só há pouco tempo a Igreja Católica exalta o amor conjugal a exemplo dos Protestantes, mas ainda condena o uso de contraceptivos. Em outras palavras, ainda não aprova o exercício da sexualidade sem finalidades reprodutivas.

"O que mais se pode pedir além de afogar-se na enorme onda do amor, e ser derrotado como ser humano, mas ser vitorioso como alguém capaz da amar. Amantes de Deus, amantes de outros seres humanos, das criaturas grandes ou pequenas! Na aparente derrota do amor, renascemos de novo, a esta é a única razão que temos para continuar na Terra “. 


\title{
1.4. O Renascimento: amor conjugal $\mathrm{x}$ amor filial
}

"Vai, come com alegria o teu pão e bebe gostosamente o teu vinho... Goza a vida com a mulher que amas, todos os dias da tua vida fugaz..."

(Eclesiastes, 9,7,9).

Os teólogos receavam que a austeridade excessiva poderia fazer o casamento perder o seu papel social. Houve então um certa liberalização dos costumes o que trouxe efeitos benéficos para a estabilidade do casamento.

Com o início da industrialização, a família vai deixando de ser uma unidade de produção para passar a ser unidade de consumo: Dentro desse contexto é interessante limitar o número de filhos.

"Do século XVI ao século XIX, as contradições se agravam entre o direito sexual dos esposos e seus deveres para com seus filhos, e esse processo me parece ter favorecido a introdução da concepção no comércio conjugal" (Flandrin, 19813).

OS filhos podem ser um fator de união e intensificação do amor de um casal. Mas a sua presença também pode trazer à tona conflitos geradores de tensão quando não bem compreendidos. Assim, a chegada dos filhos provoca muitas mudanças na vida do casal.

Muitos casais voltam toda a sua energia para os cuidados e educação dos filhos e se esquecem de cuidar do amor e da sedução necessários para a saúde da relação. Enganam-se pensando que o amor dos adultos não necessita tanta dedicação e investimento. Acontece que acabam se distanciando como namorados e a relação pode se tornar bastante fragilizada. Algumas relações se mantém por causa dos filhos e acabam perdendo a razão de ser quando estes partem de casa.

\author{
“Filhos ... Filhos.' \\ Melhor não tê-los! \\ Mas se não os temos \\ Como sabê-los? \\ Como saber \\ Que macieza \\ Nos seus cabelos \\ Que cheiro morno \\ Na sua carne \\ Que gosto doce \\ Na sua boca”.'
}

(Vinícius de Morais) 


\subsection{A nossa época contemporânea: triunfo do desejo e do amor}

"A vida e o comportamento sexual no ser humano podem apresentar uma vasta gama de formas e maneiras de se mostrar. Tais formas e maneiras podem ser adequadas ou inadequadas dependendo do contexto cultural, social, histórico e científico".

(Rodrigues Junior, 1991)

O historiador Flandrin (1988) realizou um estudo da freqüência da palavra amor nos títulos de obras literárias e científicas. Observou que os sentidos da palavra amor variavam conforme a época dentro de um contexto mais religioso ou mais profano. Observou ainda que o estudo desse tema sempre gerou interesse. Na época atual, o sentido da palavra amor diz respeito tanto a sentimentos como afeição e ternura bem como sentidos como prazer, volúpia e gozo. "O amor é agora, no seu todo, um valor absoluto de nossa civilização. Hoje ninguém parece duvidar da santidade do amor, e sobretudo não a Igreja Católica, ao menos quando se trata de um amor verdadeiro que interessa ao mesmo tempo o espírito, o coração e a sexualidade. Nossa sociedade não aceita mais a idéia de que se possa casar, nem mesmo se continue casado, sem desejo e sem amor. E, inversamente, o casamento nos parece tanto o resultado necessário do amor, que os falsos amores levam ao divórcio e a um novo casamento" (Flandrin, 1988).

A maioria dos autores concordam com essa opinião:

"Nas famílias modernas, estudando as relações não só entre marido e mulher mas entre todos os seus membros, veremos que essas se apóiam essencialmente em laços afetivos" (Delta Torre, 1985).

"Tem havido um importante interesse dos casais contemporâneos em que a relação entre os envolvidos tenha por eixo cada vez mais o desejo recíproco e menos a obrigação" (Turkenicz, 1995).

O que se observa atualmente é um menor número de uniões formais, mas não de união de maneira geral. Ou seja, se ampliaram as modalidades de relações de casal.

As mudanças sociais ocorridas através dos tempos, levaram a quatro tendências universais e que repercutem diretamente nessas várias modalidades de relações de casal. Vejamos cada uma delas separadamente: 


\subsubsection{O aumento da expectativa de vida}

Esse fator aumenta as chances de crise no relacionamento. Além disso, as pessoas têm maior tempo disponível para tentar novas relações.

Neste contexto, não deve nos admirar nem que as uniões livres sejam a primeira escolha quanto às modalidades de relações de casal, nem que tenham aumentado significativamente o número de separações. As uniões livres deixam os protagonistas com mais agilidade seja para juntar-se, seja para separar-se.

\subsubsection{Diminuição don índices de natalidade}

O grau crescente de preocupação dos pais com seus filhos, o custo da educação e pouco tempo disponível dos pais por ambos trabalharem fora, determinam uma necessidade da limitação no número de filhos. Concomitantemente, há um avanço na tecnologia dos contraceptivos. A diminuição da fecundidade faz com que a procriação não seja o elemento central do casal.

"Faz sentido a vida em casal mesmo quando por opção dos interessados, não sejam gerados filhos" (Turkenicz, 1995).

\subsubsection{Maior participação das mulheres no mercado de trabalho}

Esse fato trouxe grandes e profundas mudanças para o casal e para a estrutura familiar. A mulher passa a ser independente e colaborar no orçamento doméstico. For outro lado, as crianças ficam mais sozinhas necessitando de creches ou babás. Nos homens há um misto de alívio, por não serem mais os únicos responsáveis pela manutenção do lar, e de insegurança por sua mulher ter se tornado mais independente. Para as mulheres, essa situação traz uma série de conflitos e um acúmulo de tensões pela dupla jornada.

\subsubsection{Aumento dos índices de divórcio}

Os adeptos da natureza indissolúvel do casamento vem diminuindo de maneira significativa. Ao ir desaparecendo o caráter sagrado do casa- 
mento, conseqüentemente diminuem também os sentimentos de culpa por uma eventual separação, tirando desta o caráter de sinistro. As separações consensuais passam a ser mais comuns e encaradas com mais naturalidade pela sociedade. Isso diminui o impacto psíquico sobre os casais separados que muitas vezes sentem-se até mesmo mais livres e aliviados com a separação.

\section{CASAIS CONTEMPORÂNEOS: UM COMPLICADO CAMINHO POSSÍVEL}

"A mecanização do sexo, a vivência sexual precoce sem nenhum preparo, a gravidez indesejada, o sexo utilizado pelo homem para competir e pela mulher para mostrar que é liberada, o sexo usado para consumo dos mais diferentes produtos e a desvinculação do afeto do sexo, são frutos de uma reação à repressão sexual que vivemos durante décadas. Como a maioria das reações a situações muito opressoras, ela vem violenta e desequilibrada. Numa próxima evolução, chegaremos ao sexo sem medo e sem culpa, como fonte de enriquecimento da pessoa" (Suplicy, 1983).

A nossa época carrega as marcas das épocas anteriores e é caracterizada por uma grande ambigüidade na esfera sexual.

A mulher já não aceita uma vida sem prazer sexual. For outro lado, ainda sente o peso da repressão e tem receio de ser desvalorizada socialmente se ousar um comportamento sexual mais liberado.

Para os homens, a dificuldade é conjugar o erotismo e a ternura. Foram educados numa época onde esses sentimentos eram dissociados. E agora são cobrados pela sociedade e pelas suas parceiras para associálos.

Estamos todos aprendendo a não há como buscar receitas nos livros dos nossos pais ou avós, pois os valores são outros. A alternativa que os casais buscam é procurarem juntos a melhor forma de se relacionarem nos dias de hoje. Daí a razão de tão diversos padrões de modalidade de relacionamento de casais.

Os adolescentes brasileiros dos anos 90 também inventaram a sua fómula de ir experimentando a companhia do sexo oposto e as atividades eróticas iniciais: "o ficar".

"Descreve-se como ficar uma modalidade de relacionamento que Possivelmente já existia antes, mas que são os adolescentes brasileiros dos anos 90 que conseguem dar-lhe um nome, eliminar os eventuais 
ingredientes condenatórios por seu caráter efêmero e superficial e, através do seu uso, consagrá-lo no vocabulário, podendo então nomear relações deste cunho, mesmo que não ocorram entre adolescentes" (Turkenicz, 1995).

$\mathrm{O}$ advento da A.I.D.S e da informática também provocam mudanças nas relações de casal. Parece que a A.I.D.S. funciona como um freio à prática érotica do tipo "Quanto mais, melhor".

A informática trouxe a alternativa de propiciar aos seus usuários a oportunidade de realizarem suas fantasias sexuais sem riscos de se contrair doenças. Como desvantagem, as pessoas ficam mais isoladas do convívio social e muito voltadas para si mesmas.

\section{ENQUANTO FOR BOM}

O que se observa atualmente é que a união em casal vem, cada vez mais, sendo um assunto apenas dos diretamente interessados.

"A constituição do casal já não necessariamente une mais duas famílias mas sim duas pessoas" (Turkenicz, 1995).

Tanto as uniões coma as separações levam em conta, cada vez mais, os sentimentos dos protagonistas.

A formalização legal da união vem sendo preterida por muitos casais por diversas razões. Porque isso expressa o desejo de outros familiares mais do que do próprio casal, na maioria das vezes. Alguns casais sentem que a moldura legal para o sentimento amoroso acaba aprisionando-os. Outros ainda consideram que a união legal torna-se um complicador considerando a perspectiva possível de uma separação.

A tendência das relações atuais é uma obrigatoriedade de durar por toda a vida, mas sim enquanto for boa. Porém a cada nova relação, os protagonistas renovam também as esperanças na vida em comum. As pessoas buscam na relação de casal ampliar seus horizontes e enriquecer-se como seres humanos. A relação continua enquanto houver desejo recíproco para tanto.

"Que não seja imortal, posto que é chama Mas que seja infinito enquanto dure ".

(Vinícius de Morais) 


\section{CASAL E GÊNERO}

"Gênero se refere a uma construção social que alude às características culturais e psíquicas e ao significado que cada sociedade atribui, de fórma diferenciada, a mulheres e homens (valores, sentimentos, condutas, etc.)".

(Turkenicz, 1995)

Com as mudanças sociais e econômicas que se produziram ao longo deste século, os papéis de gênero deixaram de ter o valor e o sentimento social que lhe eram atribuído antes.

A tecnologia dos eletrodomésticos e as escolas substituiram parte das funções das mulheres como donas de casa e mães. Estas deixaram de ser valorizadas e estão perdendo o seu lugar e o seu papel na sociedade. Ao mesmo tempo, a exigência social de que a mulher exerça um trabalho rendoso fora do lar e a expectativa de que tenha um comportamento sexual mais liberal, podem gerar conflitos, angústias e insegurança para a mulher que não foi educada para isso.

Uma sensação de insatisfação decorrente desses fatores é comum na mulher moderna. E ela pode erroneamente culpar o seu relacionamento quando a problemática é bem mais complexa. Observamos pessoas trocando de parceiros como se isso fosse a solução de seus problemas e não a resolução dos próprios conflitos em meio a tantas mudanças sociais.

Há mulheres culpadas por gostarem de ser apenas donas de casa. Há mulheres culpadas que, apesar de terem potencial, parecem não conseguir êxito na carreira profissional. Enfim, a mulher ainda está em busca de definições para o seu papel na sociedade atual. O homem, por sua vez, pode ajudá-la para com amor e compreensão, reencontrarem o caminho perdido.

"Que haja espaços na vossa junção.

E que os ventos do céu dancem entre vós.

Amai-vos um ao outro, mas não façais do amor um grilhão:

Que haja, antes, um mar ondulante entre as praias de vossa alma.

Dai o vosso coração, mas não o confieis à guarda um do outro.

Pois somente a mãe da Vida pode conter vosso coração

E viveis juntos, mas não vos aconchegueis demasiadamente:

Pois as colunas do Tempo erguem-se separadamente.

E o carvalho e o cipreste não crescem à sombra um do outro”.

(Kalil Gibran) 


\section{CONSIDERAÇÕES FINAIS: O NAMORO APESAR DA CRISE}

OS sentimentos de solidariedade e cumplicidade talvez sejam os principais responsáveis pela alegrias da vida em comum. $\mathrm{O}$ amparo e o conforto de uma relação de casal satisfatória faz com que as pessoas continuem apostando e se arriscando nessa opção.

A maioria dos terapeutas de casais considera que o exercício da Sexualidade seja um ingrediente básico para a manutenção do vínculo e da qualidade da relação. Pequenos gestos, olhares, presentes e atenções garantem a permanência do desejo e do prazer, da alegria e encantos da vida a dois.

Mas em meio a toda essa crise social, pacotes e planos econômicos, as pessoas por vezes não encontram tempo, lugar e disposição para namorar.

"Namorados, namorados, não os vejo mais alados, sublimes, alcandorados, nos mirífcos estados de êxtases multiplicados em horizontes dourados de mundos ensolarados. Estais casmurros, calados entre carinho cansados e sonhos desanimados. Que vos sucedeu, coitados? Acaso foram arquivados os projetos encantados, alvo de finos cuidados, pelos dois armazenados? Onde os férvidos agrados, os toques maravilhodos de vossos dias passados Namorados, namorados, deixais-no desarvorados!

Diviso em vossos semblantes, diversos dos crepitantes, abertos e fulgurantes sinais festivos de antes. Já não sois doces amantes, não carregais, exultantes o suave peso de instantes 


\begin{abstract}
que pareciam diamantes nos volteios elegantes dos jogos inebriantes e nos beijos delirantes quando adultos são infantes buscanclo refrigerantes inda são mais excitantes. Já não sois os bandeirantes de descobertas faiscantes. Diviso em vosso semblantes amarguras humilhantes.
\end{abstract}

Chegou-me a resposta no ar, após muito meditar e livros mil consultar: A inflação tentacular, com guantes de arrebentar, ferrou-vos na jugular. Vosso anseio de morar em casinha à beira-mar ou qualquer outro lugar desféz-se tio limiar. A recessão de lascar nem vos deixa respirar, e de empregos, neste andar, quem ousa mais cogitar? Um pacote singular De rigidez tumular desaba no patamar da pretensão de casar. Chegou-me a resposta no ar: não dá mais pra namorar”.

(Carlos Drummond de Andrade)

Talvez o antídoto para esse pessimismo seja só esse mesmo: o amor. Tentar encontrá-lo a sobretudo preservá-lo em meio a essa crise toda é tarefa para heróis. Que tentemos sê-los! 


\section{REFERÊNCIAS BIBLIOGRÁFICAS}

1. EELCHIOR, A. C. in Fascinação. E1is Regina (Como nossos pais) Polygram; 1989.

2. BLANC, M. Os herdeiros de Darwin. São Paulo, Ed. Página Aberta Ltda, 1994.

3. DELLA TORRE, M. B. L. O homem e a sociedade. São Paulo, Ed. Nacional, 1985.

4. DRUMMOND DE ANDRADE, C. Amar se aprende amando (A lamentável história dos namorados). Rio de Janeiro, Ed. Record, 1985.

5. ENCICLOPÉDIA MITOLOGIA. São Paulo, Ed. Abril Cultural, vol. I.

6. FLANDRIN, J. L. O sexo e o ocidente. São Paulo, Ed. Brasiliense, 1988.

7. GIBRAN, K. O profeta. Rio de Janeiro, Ed. Record.

8. GOETHE, J. W. D. in GAARDER, J. O mundo de Sofia. São Paulo, Cia de letras; 1995, p. 180.

9. MILlER, H. in Folha de S. Paulo-Maktub (Paulo Coelho). 10/1 1/95.

10. MORAES, V. Antologia Poética. Rio de Janeiro, Ed. José Olympio, 1979, p. 77, Soneto de Fidelidade; p. 161, Poema Enjoadinho.

11. REICH, W. A função do orgasmo. São Paulo, Ed. Erasiliense, 1987.

12. RODRIGUES JUNIOR, O. M. Objeto do desejo. São Paulo, Ed. Iglu, 1991.

13. SHINYASHIKI, R. Mistérios do coração. São Paulo, Ed. Gente, 1990.

14. SUPLICY, M. Conversando sobre sexo. Rio de Janeiro, Ed. Voles, 1983.

15. TURKENICZ, A.- A aventura do casal. Porto Alegre, Ed. Artes Médicas, 1995. 